\title{
GROWING STATE-FEDERAL CONFLICTS IN ENVIRONMENTAL POLICY: THE ROLE OF MARKET-BASED REGULATION
}

\author{
Roberton C. Williams III \\ Working Paper 16184 \\ http://www.nber.org/papers/w16184 \\ NATIONAL BUREAU OF ECONOMIC RESEARCH \\ 1050 Massachusetts Avenue \\ Cambridge, MA 02138 \\ July 2010
}

For their helpful comments and suggestions, I thank Julie Cullen, Roger Gordon, Michael Keen, Monica Singhal, and participants in the NBER Conference on Fiscal Federalism. The views expressed herein are those of the author and do not necessarily reflect the views of the National Bureau of Economic Research.

NBER working papers are circulated for discussion and comment purposes. They have not been peerreviewed or been subject to the review by the NBER Board of Directors that accompanies official NBER publications.

(C) 2010 by Roberton C. Williams III. All rights reserved. Short sections of text, not to exceed two paragraphs, may be quoted without explicit permission provided that full credit, including @ notice, is given to the source. 
Growing State-Federal Conflicts in Environmental Policy: The Role of Market-Based Regulation Roberton C. Williams III

NBER Working Paper No. 16184

July 2010

JEL No. D62,H23,H77,Q58

\begin{abstract}
$\underline{\text { ABSTRACT }}$
In recent years, cases in which state governments chose to override federal environmental regulation with tighter regulations of their own have become increasingly common, even for pollutants that have substantial spillovers across states. This paper argues that this change arose at least in part because of a shift in the type of regulation used at the federal level, from command-and-control regulation toward more incentive-based regulation. Under an incentive-based federal regulation, a state imposing a tighter regulation will bear only part of the additional cost, and thus has more incentive to tighten regulation than it does under federal command-and-control. This difference helps to explain observed patterns of regulation. In addition, it has implications for the choice of regulatory instruments. For a pollutant that causes both local and spillover damage, a federal pollution tax is likely to yield a more efficient outcome than federal command-and-control policy or a federal system of tradable permits.
\end{abstract}

Roberton C. Williams III

Department of Agricultural and Resource Economics

University of Maryland,

Symons Hall

College Park, MD 20742

and NBER

rwilliams@arec.umd.edu 
Early in the history of U.S. environmental regulation by the federal government, cases in which state governments chose to override federal regulation with tighter regulations of their own on the same pollutant were quite rare. In recent years, however, these cases have become more common, even for pollutants that have substantial spillovers across states (and thus for which one would expect the federal government to regulate more aggressively). Moreover, when California attempted in the mid-to-late 2000's to impose its own car and truck fueleconomy regulations, the federal government acted to block those rules. Why have these conflicts in environmental regulation become more common?

This paper argues that this change arose at least in part because of a shift in the type of regulation used at the federal level, from command-and-control regulation toward more incentive-based regulation. These two types of regulation at the federal level provide substantially different incentives for state regulation. Under federal command-and-control, a state that imposes a tighter standard than the federal government will bear the full cost of that tighter standard. In contrast, under an incentive-based federal regulation, a state imposing a tighter regulation will bear only part of the additional cost, because of an offsetting reduction in emissions taxes paid or emissions permits bought within the state. Consequently, under incentive-based federal regulation, states will be much more inclined to impose their own tighter policies than under federal command-and-control.

Prior work on environmental federalism has not recognized this difference. Most models in the environmental federalism literature assume that all regulations take the form of emissions caps, rather than incentive-based policies. And the relatively small number of environmental federalism papers that compare the effects of incentive-based and command-and-control regulation (e.g., Wellisch, 1995) assume that regulation is done entirely by the federal 
government or entirely by state governments, but do not consider the case in which both levels of government can choose to regulate the same pollutant.

By pointing out this difference and exploring its implications, this paper makes three main contributions. First, this difference helps to explain observed patterns of regulation, and thus improves our understanding of environmental regulation in a federal system. Second, recognizing this difference helps to guide policy. One implication of these results is that for a pollutant that causes local damage and also has inter-state spillovers, a federal pollution tax is likely to yield a more efficient outcome than federal command-and-control policy or a federal system of tradable permits.

The third contribution is broader: the simple framework developed in this paper could also be applied to look at issues of federalism in contexts other than environmental policy. For example, the comparison between unfunded mandates and matching grants in the context of public good provision is analogous to the comparison between command-and-control regulations and environmental taxes.

The next section of this paper introduces a very simple model of environmental regulation in a federal system. The following three sections use that model to analyze cases in which only the national government can regulate emissions, cases in which only the state governments can regulate, and cases in which both levels of government can regulate the same pollutant simultaneously. A final section concludes and discusses policy implications and avenues for future research.

\section{A Simple Model}

This section introduces a very simple model of environmental regulation in a federal setting. It considers one large jurisdiction made up of $N$ smaller jurisdictions. Throughout the 
paper, I will refer to the large jurisdiction as a nation and the smaller jurisdictions as states. But this is just convenient terminology: the model is general, and could just as easily represent nations within a larger federation, as in the European Union, or towns within a state.

Emissions from state $i$ are denoted as $e_{i}$. The cost of emissions reductions in state $i$ is given by the function

(1) $\quad C_{i}\left(e_{i}\right)$

which is decreasing and concave in $e_{i}$, or in other words, achieving a lower level of emissions implies a higher cost, and the marginal cost of reducing emissions rises as the level of emissions falls. For simplicity, assume that the second derivative of $C_{i}\left(e_{i}\right)$ is constant and is equal across all states (i.e., the marginal cost of emissions reductions is linear and has the same slope for every state). ${ }^{1}$

This cost function could represent many different methods for reducing emissions, from reducing output from polluting industries or consumption of polluting goods to installing end-ofpipe emissions control equipment.

One key implicit assumption embodied in this function is that the cost of achieving a given reduction in emissions is the same under command-and-control as under incentive-based regulation. There are many reasons why this might not be the case. For example, incentivebased regulations induce a cost-effective allocation across different methods of reducing emissions, whereas achieving a similarly cost-effective allocation under command-and-control requires the regulator to know the details of firms' cost functions. But assuming away any such cost differences allows this paper to focus on other important differences between commandand-control and incentive-based regulation.

\footnotetext{
${ }^{1}$ This assumption produces substantially simpler expressions for many of the paper's results, but is not qualitatively important.
} 
A second key implicit assumption in (1) is that the cost of emissions reductions in one state does not depend on emissions reductions in any other state, thus ruling out any cost-side spillovers. This assumption will be relaxed later in the paper.

Pollution damage in state $i$ is determined by the function

$$
D_{i}\left(e_{i}, E\right) \text {, }
$$

where $E$ is the aggregate nationwide level of emissions, given by

$$
E=\sum_{i} e_{i}
$$

This damage function is weakly increasing in both arguments, and the second derivatives are non-negative.

Making damages a function both of local emissions and of national emissions allows this model to represent a pollutant with strictly local effects (in which case $\partial D_{i} / \partial e_{i}>0$ and $\partial D_{i} / \partial E=0$ ), one with strictly national effects (in which case $\partial D_{i} / \partial e_{i}=0$ and $\partial D_{i} / \partial E>0$ ), or the most interesting case, a pollutant with both local and national effects (in which case both partial derivatives are positive). This last case could be a single pollutant with both local and national effects, or could be two different pollutants, one local and one national, which are identically affected by efforts to reduce emissions. ${ }^{2}$

This model considers two general classes of regulations: command-and-control regulation and incentive-based regulation. And it considers three cases for the division of regulation between the two levels of government: a case in which only the national government

\footnotetext{
${ }^{2}$ For example, reducing motor vehicle use will reduce emissions of local air pollutants such as nitrogen oxides (NOx) and volatile organic compounds (VOCs) and will simultaneously reduce emissions of carbon dioxide (CO2), which contributes to global climate change. Because other methods of reducing emissions will affect these pollutants differently (e.g., a catalytic converter reduces NOx and VOCs, but has no effect on CO2 emissions), the assumption that these pollutants are perfectly correlated is not strictly realistic. But it represents a convenient simplification.
} 
regulates emissions, a case in which only the state governments regulate emissions, and a case in which both levels of government regulate simultaneously.

Under command-and-control regulation, the government chooses a cap on emissions. The emissions cap set by state $i$ is denoted $q_{i}$. The cap set by the national government on emissions from state $i$ is denoted $Q_{i}$. For the cases in which only one level of government regulates emissions, under command-and-control regulation $e_{i}$ will equal the emissions cap $q_{i}$ or $Q_{i}$. For the case in which both levels of government simultaneously regulate emissions using command-and-control, emissions will be determined by the tighter standard, and thus

$$
e_{i}=\min \left(q_{i}, Q_{i}\right)
$$

Under an emissions tax, the tax rate imposed by the state government is denoted $\tau_{i}$, and the tax rate imposed by the national government is $T_{i}$. Consumers and firms respond to the tax by reducing emissions up to the point where the marginal cost of reducing emissions equals the combined tax rate, so emissions are determined by

$$
-\frac{\partial C_{i}}{\partial e_{i}}=\tau_{i}+T_{i}
$$

Each state government returns all emissions tax revenue lump-sum within its state. The national government also returns emissions tax revenue lump-sum, allocated across states such that state $i$ receives the share $r_{i}$ of a marginal dollar of national-level emissions tax revenue, with these shares adding up to one:

$$
\sum_{i} r_{i}=1
$$

Regulation via a system of tradable permits would look very similar, but $\tau_{i}$ and $T_{i}$ would represent permit prices rather than tax rates, and government would indirectly determine that 
permit price by setting the number of permits. The share $r_{i}$ then represents the fraction of permits allocated to state $i$. For the cases in which only one level of government regulates emissions, tradable permits will yield the same result as taxes. However, when both levels of government regulate emissions, permits may yield a different result, as will be shown later in the paper.

\section{Regulation by the National Government}

This sub-section considers regulation only by the national government. Many of the results in this case are fairly obvious and duplicate some results from the existing literature on environmental federalism, but going through them first makes it easier to follow some of the less-obvious results that come later.

The national government sets regulations to minimize the sum over all states of pollution damage plus the costs of reducing emissions, given by

$$
\sum_{i}\left[C_{i}\left(e_{i}\right)+D_{i}\left(e_{i}, E\right)\right]
$$

Note that emissions taxes (state or national) do not appear in this objective. Those taxes represent a cost for polluters, but that cost is exactly offset by the value of the lump-sum return of tax revenue. ${ }^{3}$ This objective assumes that the national government is attempting to maximize efficiency. Various positive political economy models might suggest alternative objectives, but this paper focuses only on cases in which all levels of government aim to maximize welfare for their constituents.

Under command-and-control, to get the national government's first-order condition for $Q_{i}$ (the emissions cap on state $i$ ), substitute (3) and $e_{i}=Q_{i}$ into (7), take the derivative with

\footnotetext{
${ }^{3}$ A similar argument applies to tradable permits.
} 
respect to $Q_{i}$, set the result equal to zero and rearrange. This gives

$$
-\frac{\partial C_{i}}{\partial e_{i}}=\frac{\partial D_{i}}{\partial e_{i}}+\sum_{j} \frac{\partial D_{j}}{\partial E} .
$$

Thus, the emissions cap will be set such that the marginal cost of emissions reductions in state $i$ equals the marginal damage from pollution emissions in state $i$ (which in turn equals the local damage in state $i$ plus the national-level effects on all states). This is the first-best level of emissions.

Under the emissions tax, the national government's first-order condition will be the same. To show this, substitute (3) into (7), take a total derivative of the result with respect to $T_{i}$, divide through by $\frac{d e_{i}}{d T_{i}}$, set equal to zero, and rearrange to get (8). The government can then satisfy this first-order condition by setting the tax equal to marginal damage:

$$
T_{i}=\frac{\partial D_{i}}{\partial e_{i}}+\sum_{j} \frac{\partial D_{j}}{\partial E}
$$

Similarly, the national government could use tradable permits to satisfy (8) by setting up a permit system that produces permit prices that follow (9). ${ }^{4}$ Thus, any of the instruments can achieve the first-best level of emissions in each state, a result that is not at all surprising.

Of course, all of this assumes that the national government can set different policies for different states. Suppose instead that it must set policy such that the marginal cost of emissions reductions is not differentiated across states: that is, it must set emissions caps such that each state faces the same marginal cost of emissions reductions, set the emissions tax to a single

\footnotetext{
${ }^{4}$ Note though that this will in general require either that permits cannot be traded across state lines - in which case under this model's assumptions it is identical to a set of emissions caps - or that such trades occur at a ratio other than one-to-one.
} 
national rate, or allow one-for-one permit trading among all states. ${ }^{5}$ In this undifferentiated case, the first-order condition for can be shown (following the same steps used to derive (8)) to be

$$
-\frac{\partial C_{i}}{\partial e_{i}}=\frac{1}{N} \sum_{j}\left(\frac{\partial D_{j}}{\partial e_{j}}+\sum_{k} \frac{\partial D_{k}}{\partial E}\right)=\frac{1}{N} \sum_{j} \frac{\partial D_{j}}{\partial e_{j}}+\sum_{j} \frac{\partial D_{j}}{\partial E}
$$

In this case, marginal cost equals the average marginal damage across states. Not surprisingly, this generally will not yield the first-best level of emissions, because the government has only one policy instrument with which to regulate $N$ different externalities. The only exception would be the case in which the marginal damage from local pollution $\frac{\partial D_{j}}{\partial e_{j}}$ is the same for all states. In that case, there is no need for a differentiated policy, because marginal damage is the same everywhere.

This undifferentiated case could also represent a case in which the government can differentiate policy, but knows only the aggregate distribution of damage functions and is uncertain about any particular state's damage function. This would also lead to the first-order condition in (10).

\section{Regulation by State Governments}

In the absence of federal regulation, each state government sets regulations to minimize the cost to that state of reducing emissions plus pollution damage to that state:

$$
C_{i}\left(e_{i}\right)+D_{i}\left(e_{i}, E\right)
$$

\footnotetext{
${ }^{5}$ The constraint that national policy cannot be differentiated across states is commonly assumed in the environmental federalism literature, and parallels similar assumptions in the broader fiscal federalism literature (see Oates, 1999). Often for an emissions cap this assumption requires that the cap be equal across states. But this is highly unrealistic: command-and-control policies are applied at the firm or facility level, and thus it seems more reasonable to assume that they equalize marginal costs across states than that they equalize the quantity of emissions across states. It also means that in the absence of state policy, an undifferentiated national emissions cap achieves the same allocation of emissions as an undifferentiated tax or permit system. Equalizing costs in this way makes it easier to focus on other differences among instruments.
} 
Just as in the national case, state-level emissions taxes don't appear in the objective function, because the value of the returned revenue exactly offsets the cost of the tax. Note also that the incidence of emissions taxes and emissions control expenses in state $i$ is assumed to fall entirely on the residents of that state. ${ }^{6}$

Following the same set of steps as in the national government case shows that the firstorder condition for command-and-control regulation at the state level is

$$
-\frac{\partial C_{i}}{\partial e_{i}}=\frac{\partial D_{i}}{\partial e_{i}}+\frac{\partial D_{i}}{\partial E}
$$

Thus, states will set emissions such that marginal cost equals marginal damage, but including only damage within the state, not damage to other states. As in the national government case, the first-order condition under the emissions tax or emissions permits is the same as under command-and-control, and can be satisfied by setting the tax rate equal to marginal damage (the right-hand side of 12) or setting the quantity of permits such that the permit price equals marginal damage. Under any type of regulation, state regulation will generally not achieve the first-best, because state-level regulation fails to take into account damage to other states. Only in the case of a strictly local pollutant (for which $\frac{\partial D_{i}}{\partial E}=0$ ) will state-level regulation yield a firstbest outcome. This is an example of the well-known result that local regulation is not efficient when there are inter-jurisdictional spillovers.

\section{Regulation by Both National and State Governments}

This sub-section considers the cases in which both the national and state governments simultaneously regulate the same pollutant. For simplicity, this is modeled as a one-shot,

\footnotetext{
${ }^{6}$ There are many reasons why some portion of the costs of emissions taxes or control expenses might fall on those outside the state (e.g., if pollution-intensive production uses a fixed factor owned in part by out-of-state residents). But it is useful to focus on the case in which the cost is borne entirely within the state.
} 
simultaneous-move game. That is, this section focuses on the Nash equilibria (or refinements thereof) of games in which the national government and all state governments simultaneously set environmental policy.

\section{A. Simultaneous Regulation under Emissions Caps}

First, consider the case in which the states and national government choose emissions caps simultaneously. The Nash equilibrium strategy for the national government will minimize its objective (7), taking state policies as given. If the national government chooses a higher emissions cap than the state does (i.e., $Q_{i}>q_{i}$ ), then the national cap won't bind, and a marginal change in $Q_{i}$ will have no effect. If the national cap does bind, then the national government's first-order condition is the same as when only the national government regulates emissions, which is equation (8). Therefore, setting the national caps based on (8) is a weakly dominant strategy.

The equilibrium strategy for each state government will be similar. If the state cap is looser than the national cap, then it won't bind. If the state cap does bind, then the state government's first-order condition is the same as when only the state government regulates, which is equation (12). Thus, setting the state cap based on (12) is a weakly dominant strategy. ${ }^{7}$

Examination of (8) and (12) shows that if $\sum_{j \neq i} \frac{\partial D_{j}}{\partial E}>0$, or in other words, if there are harmful spillovers to other states, then the national cap for state $i$ will be set more tightly than the state cap. Thus, the Nash equilibrium allocation of emissions will be the same as if only the

\footnotetext{
${ }^{7}$ Because these strategies are only weakly dominant, there are many Nash equilibria: one in which all governments choose weakly dominant strategies, plus many others in which one or more non-binding caps are set at levels other than the weakly dominant level. A trembling-hand refinement eliminates the latter type of equilibrium. More importantly, all of these equilibria yield the same allocation of emissions.
} 
national government were regulating emissions, which achieves the first-best, as shown earlier. ${ }^{8}$ The same outcome will occur if the national government imposes emissions caps and the state governments use emissions taxes (or tradable permits).

Now consider the case in which the national government is constrained to use an undifferentiated cap (again, this does not imply that each state is constrained to the same amount of emissions, but that the marginal cost of emissions reductions is constrained to be equal across states). Just as in the differentiated case, only the tighter emissions cap will bind. In this case the national first-order condition is

$$
-\frac{\partial C_{i}}{\partial e_{i}}=\frac{1}{N_{\beta}} \sum_{j \in \beta}\left(\frac{\partial D_{j}}{\partial e_{j}}+\sum_{k} \frac{\partial D_{k}}{\partial E}\right)=\frac{1}{N_{\beta}} \sum_{j \in \beta} \frac{\partial D_{j}}{\partial e_{j}}+\sum_{j} \frac{\partial D_{j}}{\partial E}
$$

where $\beta$ is the set of states for which the national cap will bind and $N_{\beta}$ is the number of states in that set. This condition is similar to the analogous condition for the case in which only the national government regulates emissions, equation (10), except that rather than averaging marginal damages over all states, the average covers only those states in which the national cap will bind, because those are the only states in which the national cap has any effect on emissions.

The equilibrium strategy for each state government remains the same as in the differentiated case: the weakly dominant strategy is to set the state cap based on (12), the same first-order condition as in the case in which only the states regulate emissions. And as before, the state first-order condition would be the same if the national government uses an emissions cap and the states use emissions taxes.

\footnotetext{
${ }^{8}$ If the net spillovers are positive (i.e., $\sum_{j \neq i} \frac{\partial D_{j}}{\partial E}<0$ ) for at least one state, then this equilibrium will not achieve the first-best, because that state will set too tight a cap. But in that case, the national government could restore the firstbest outcome by setting an emissions floor for that state.
} 
Comparing (12) and (13) shows that in equilibrium, the national cap will bind in every state $i$ for which

$$
\frac{\partial D_{i}}{\partial e_{i}}<\frac{1}{N_{\beta}} \sum_{j \in \beta} \frac{\partial D_{j}}{\partial e_{j}}+\sum_{j \neq i} \frac{\partial D_{j}}{\partial E} .
$$

That is, the national cap will be set more tightly than the state cap if local damages in state $i$ are less than the average local marginal damages in states where the national cap binds plus the total over all states other than $i$ of the marginal damage from aggregate emissions. The intuition is that spillover damages push the national government to set the cap tighter than what individual states would choose, but because the national cap is set based on the average marginal damage for states affected by that cap, a state with relatively high local marginal damages may want to set a tighter cap. ${ }^{9}$

This equilibrium will generally not yield the first-best emissions allocation, except if local marginal damages are equal for all states in which the national cap binds, and spillovers are zero for all states in which the state cap binds. Nonetheless, as long as spillovers aren't positive, this equilibrium will be at least as efficient as the case in which the national government uses an undifferentiated policy and states don't regulate, because in any case in which the state caps bind, they will move the level of emissions closer to the efficient level.

The national cap will bind on all states (i.e., (14) will hold for every state) if

$$
\frac{\partial D_{i}}{\partial e_{i}}-\frac{1}{N-1} \sum_{j \neq i} \frac{\partial D_{j}}{\partial e_{j}}<\sum_{j \neq i} \frac{\partial D_{j}}{\partial E} \quad \forall i
$$

\footnotetext{
${ }^{9}$ Note that again there may be multiple Nash equilibria, and in this case they can lead to different emissions allocations, because the right-hand sides of (13) and (14) depend on the set of states in which the national cap binds. A trembling-hand refinement eliminates nearly all of these, because it rules out any equilibria in which a state chooses a weakly dominated level of its emissions cap. Even with this refinement, there may be multiple levels of the national cap that satisfy (13), each with a different set of states in which the national cap is binding. However, the national government will generally prefer one of these over the others, leading to a unique equilibrium.
} 
that is, if for every state, the difference in local marginal damages between that state and the average is smaller than the marginal damage aggregate emissions cause in other states. This will tend to occur when there is relatively little heterogeneity across states in local marginal damage or when spillovers are relatively large.

Expression (15) suggests that cases in which states impose tighter standards than the federal cap may well be relatively rare. And it also suggests that these cases will appear most often for pollutants that are primarily local and for which the local marginal damages vary substantially across states.

Cases in which U.S. states have set tighter regulations than the federal standards do appear to be relatively rare, but Oates $(2001$, p. 15) cites a few examples. These include the Toxic Substances Control Act, the Federal Insecticide, Fungicide, and Rodenticide Act, and hazardous waste disposal rules under the Resource Conservation and Recovery act. In each case, these are largely local pollutants. And it is quite plausible that local marginal damages could vary significantly across states. Thus, these cases seem consistent with the model's results.

\section{B. Simultaneous Regulation under Emissions Taxes}

Next, consider the case in which both state and national governments regulate emissions via emissions taxes. In the differentiated case, the national government's first-order condition will again follow equation (8), the same first-order condition as in all of the differentiated cases considered thus far. In this case, though, satisfying (8) requires setting the emissions tax equal to marginal damage minus the state emissions tax rate:

$$
T_{i}=\frac{\partial D_{i}}{\partial e_{i}}+\sum_{j} \frac{\partial D_{j}}{\partial E}-\tau_{i}
$$


The state government's first-order condition will differ from previous cases because the state's objective changes somewhat in the presence of a national emissions tax. The national pollution tax appears in the state's objective, because the national taxes paid by that state are not necessarily offset by the revenue returned to that state. Just as before, the objective includes the cost to that state of reducing emissions plus pollution damage in that state. But in this case it also adds the national emissions tax paid by that state net of the national emissions tax revenue returned to it. Thus, state $i$ 's objective becomes

$$
C_{i}\left(e_{i}\right)+D_{i}\left(e_{i}, E\right)+T_{i} e_{i}-r_{i} \sum_{j} T_{j} e_{j}
$$

To get the first-order condition for state $i$, follow the same set of steps used to derive the state first order condition in previous cases (equation (12)). This yields

$$
-\frac{\partial C_{i}}{\partial e_{i}}=\frac{\partial D_{i}}{\partial e_{i}}+\frac{\partial D_{i}}{\partial E}+\left(1-r_{i}\right) T_{i},
$$

This equates the marginal cost of reducing emissions with the marginal pollution damage within the state, plus the national emissions tax rate (net of return transfers to the state). This first-order condition can be satisfied by setting the state emissions tax rate equal to the right-hand side of (18) minus the national emissions tax rate $T_{i}$ :

$$
\tau_{i}=\frac{\partial D_{i}}{\partial e_{i}}+\frac{\partial D_{i}}{\partial E}-r_{i} T_{i}
$$

The unique Nash-equilibrium tax rates are then defined by the intersection of the two reaction functions (16) and (19), which yields

$$
T_{i}=\frac{1}{1-r_{i}} \sum_{j \neq i} \frac{\partial D_{j}}{\partial E}
$$

and 


$$
\tau_{i}=\frac{\partial D_{i}}{\partial e_{i}}+\frac{\partial D_{i}}{\partial E}-\frac{r_{i}}{1-r_{i}} \sum_{j \neq i} \frac{\partial D_{j}}{\partial E}
$$

The national emissions tax is set so that the tax rate, net of return transfers to the state, equals the spillover marginal damage to other states, thus fully internalizing the inter-state externality. The state tax rate then fully internalizes the intra-state externality: the tax rate equals marginal damage within the state minus the increase in transfers to the state caused by a marginal increase in emissions. This yields a first-best allocation of emissions. And in general, it will entail nonzero tax rates from both levels of government..$^{10}$

Now consider the undifferentiated case. The national government's first-order condition in this case is

$$
T=\frac{1}{N} \sum_{i}\left[\frac{\partial D_{i}}{\partial e_{i}}+\sum_{j} \frac{\partial D_{j}}{\partial E}-\tau_{i}\right]
$$

This sets the tax equal to the average across states of marginal damage minus the state tax rate.

The states' first-order conditions are the same as in the differentiated case, so the state emissions taxes follow (19). Again, the unique Nash-equilibrium tax rates are defined by the intersection of the reaction functions (in this case, (19) and (22)). This gives

$$
T=\sum_{j} \frac{\partial D_{j}}{\partial E}
$$

and

$$
\tau_{i}=\frac{\partial D_{i}}{\partial e_{i}}+\frac{\partial D_{i}}{\partial E}-r_{i} \sum_{j} \frac{\partial D_{j}}{\partial E}
$$

In equilibrium, the national tax rate is set equal to the marginal damage from aggregate emissions $E$. If national emissions tax revenue were not returned to states, then this would over-

\footnotetext{
${ }^{10}$ For sufficiently high $r_{i}$, this equilibrium will yield a state-level subsidy rather than a tax, though in practice, this might be politically infeasible.
} 
correct the inter-state externality (which is $\sum_{j \neq i} \frac{\partial D_{j}}{\partial E}$ ). When the effect of that returned revenue is taken into account, this rate net of revenue returned equals the inter-state externality for the average state, though it may over-correct or under-correct for any particular state. And as in the differentiated case, the state tax rate fully internalizes the intra-state externality: the tax rate equals marginal damage within the state minus the increase in transfers to the state caused by a marginal increase in emissions.

Unlike in the case of emissions caps, in this case it is very likely that states will want to impose their own emissions taxes in addition to the national tax. The second and third terms on the right-hand side of (24) will sum to zero for the average state, suggesting that for a pollutant that causes any local damage, the average state will want to impose its own emissions tax.

It is difficult to find an example of a U.S. tax that is a pure environmental tax, but the taxes on gasoline and other motor fuels are probably the closest. If one broadens the definition to include other externalities, then this class would also include various "sin taxes" such as taxes on alcohol and tobacco. In every one of these cases, there is a federal tax and nearly every state government adds an additional tax of its own.

Equations (23) and (24) together (along with (5)) imply that

$$
-\frac{\partial C_{i}}{\partial e_{i}}=T_{i}+\tau_{i}=\frac{\partial D_{i}}{\partial e_{i}}+\frac{\partial D_{i}}{\partial E}+\left(1-r_{i}\right) \sum_{j} \frac{\partial D_{j}}{\partial E}
$$

If the fraction of marginal emissions tax revenue returned to a state is the same as that state's share of marginal damages from aggregate emissions (that is, if $r_{i}=\frac{\partial D_{i}}{\partial E} / \sum_{j} \frac{\partial D_{j}}{\partial E}$ ), then this undifferentiated tax will yield the first-best level of emissions in state $i$. In this case, the national 
tax net of returned revenue exactly equals the inter-state externality, thus fully internalizing that externality.

If $r_{i}$ is higher than this, then the combined tax rate will be less than marginal damages, and the level of emissions will exceed the first-best level. With a higher share of national emissions tax revenue being returned, the state has too little incentive to cut back emissions, and thus the combined tax rate is too low. For a lower value of $r_{i}$, the opposite logic applies: the state has too much incentive to reduce emissions and thus the combined rate is too high.

Note that this case may in some cases be less efficient than the earlier case in which the national government uses an undifferentiated tax and states do not regulate at all. If local marginal damage $\frac{\partial D_{i}}{\partial e_{i}}$ varies little across states, but $r_{i} \sum_{j} \frac{\partial D_{j}}{\partial E}-\frac{\partial D_{i}}{\partial E}$ varies widely, then if the national government uses an undifferentiated tax it will be more efficient not to allow states to impose their own emissions taxes. Nonetheless, in most cases it will be more efficient to have simultaneous taxation by both levels of government, particularly if $r_{i} \sum_{j} \frac{\partial D_{j}}{\partial E}-\frac{\partial D_{i}}{\partial E}$ is relatively close to zero for all states. Indeed, if the national government can set $r_{i}=\frac{\partial D_{i}}{\partial E} / \sum_{j} \frac{\partial D_{j}}{\partial E}$, then simultaneous taxation can achieve the first-best. ${ }^{11}$

These results also suggest a potentially major problem with proposals for an internationally-harmonized carbon price, such as those in Nordhaus (2006) or Cramton and Stoft (2010). These proposals are equivalent to an undifferentiated global carbon tax with the revenue raised in each country returned in full to that country (which in this model is equivalent to having

\footnotetext{
${ }^{11}$ Note that if the national government can freely choose the values of $r_{i}$, then the national policy is not really undifferentiated: the national tax rate is the same for all states, but policy can still be differentiated through the choices of $r_{i}$.
} 
$\left.r_{i}=1\right)$. The results here suggest that in this case, each country would choose to impose a local subsidy on carbon emissions to bring down the shadow price on emissions to equal the damage just within that country (which for the case of carbon is a very small fraction of the total damage). The proposals would not allow local emissions subsidies, but this incentive would remain and thus one would expect countries to adopt policies with similar effects (e.g., subsidizing carbon-intensive industries or under-regulating emissions of other pollutants that are strongly correlated with carbon emissions). This problem goes away if the carbon tax revenue is pooled across all nations and then divided up, which would give an $r_{i}$ much less than 1, but unfortunately that would also eliminate a number of the advantages of these proposals.

\section{Simultaneous Regulation under Tradable Permits}

Next, consider the case in which both state and national governments regulate emissions via tradable emissions permits. ${ }^{12}$ In the differentiated case, the national government can achieve the first-best with a system that doesn't allow permit trading across state lines, by setting the number of permits in each state to satisfy (8), the same first-order condition that applies in the differentiated case under emissions caps or emissions taxes. The equilibrium then is exactly the same as the equilibrium under differentiated emissions caps discussed earlier in the paper. ${ }^{13}$

For the undifferentiated permit policy, start by considering the case in which at least one state does not impose a binding state-level permit system. In this case, the national government's first-order condition is the same as (13), the first-order condition in the case with an undifferentiated emissions cap together with state regulation, with one subtle difference: here,

\footnotetext{
${ }^{12}$ All of the results in this section also hold if the national government uses tradable permits and states can impose emissions caps.

${ }^{13}$ The equilibrium is substantially more complicated under a differentiated permit system that permits trading across state lines, but at ratios other than one-to-one. But that case will also produce a first-best allocation of emissions.
} 
$\beta$ is the set of states for which the state regulation does not bind and thus emissions are determined by the national permit system (in that previous case, $\beta$ was described as the set for which the national cap binds, but here because of trading the national permits will bind either on all states or on none). The intuition is also the same as in that previous case: the quantity of permits will be set such that the permit price will equal marginal damage, averaged over the states where emissions are determined by the national permit system.

To get the state first-order condition, take a total derivative of the state objective (17) with respect to $e_{i}$, set equal to zero, and note that as long as the national permit system binds, the total level of emissions won't change, but the national permit price $T$ will. Rearranging the result gives

$$
-\frac{\partial C_{i}}{\partial e_{i}}=\frac{\partial D_{i}}{\partial e_{i}}+T+\left(e_{i}-r_{i} E\right) \frac{d T}{d e_{i}} .
$$

Lowering emissions raises emissions control costs, but also lowers local damages and reduces the amount spent on emissions permits. That tradeoff gives the left-hand side of (26) and the first two terms on the right-hand side. The last term recognizes that the state may gain or lose from decreasing the price of national emissions permits, depending on whether it is a net buyer or seller of permits.

Rewriting that last term using $\varepsilon$, the elasticity of demand for national emissions permits with respect to the permit price, and substituting in the national first-order condition (13) give an expression for the resulting shadow price on emissions in states with binding state permit systems:

$$
-\frac{\partial C_{i}}{\partial e_{i}}=\frac{1}{N_{\beta}} \sum_{j \in \beta} \frac{\partial D_{j}}{\partial e_{j}}+\sum_{j} \frac{\partial D_{j}}{\partial E}+\frac{\partial D_{i}}{\partial e_{i}}+\left(\frac{e_{i}}{E}-r_{i}\right) \frac{T}{\varepsilon}
$$


Note that this case can easily be less efficient than if states were not allowed to impose their own emissions regulations. The national permit price already corrects for marginal damage in the average state without a binding state permit system, and thus adding an additional state constraint will tend to push emissions below the efficient level. The second and third terms on the right-hand side of (27) together equal the efficient shadow price on emissions. Therefore, unless the fourth term is sufficiently negative to offset the first term, emissions will be held below the efficient level.

This suggests that when the national government uses a tradable permit system, it may well want to forbid states from imposing their own tighter regulations. And unlike in the case of emissions taxes, setting $r_{i}$ can't entirely solve the problem: there is no way to set $r_{i}$ such that (27 ) yields the efficient level of emissions for every state.

These results also suggest a likely conflict with states. The state first-order condition can be rewritten to show that the state permit price will follow

$$
\tau_{i}=\frac{\partial D_{i}}{\partial e_{i}}+\left(\frac{e_{i}}{E}-r_{i}\right) \frac{T}{\varepsilon}
$$

State $i$ will impose a binding state-level permit system (i.e., $\tau_{i}>0$ ) as long as the effect of lowering the national permit price (the second term in (28)) is not sufficiently negative to offset the gain from lowering local pollution damage (the first term). For the average state, the second term will be zero, so for a pollutant that causes any local damage, there will necessarily be at least one state for which $\tau_{i}>0$.

It is possible for the right-hand side of (28) to be positive for all states, indicating that all states would choose to reduce pollution below what the national system alone would do. But this would create a contradiction, because in that case the national permit system would not bind, and 
the derivations of (26) through (28) assume that it does. In this case there is a complicated set of equilibria in which the national government and all states impose permit systems, with the quantity of national permits exactly equaling the total number of state permits, and thus all are binding. If the second term on the right-hand side of (28) is sufficiently small for all states, then there is a unique trembling-hand-perfect equilibrium that yields the first-best allocation of emissions. Nonetheless, this equilibrium is quite complex and fragile, and seems unlikely to occur in practice. Thus, the case already considered, in which at least one state does not impose its own permit system, seems much more realistic.

The most prominent example of a national permit-trading system in the U.S. is the sulfur dioxide $\left(\mathrm{SO}_{2}\right)$ trading program imposed by the Clean Air Act Amendments of 1990. Appendix A of Potoski (2001) provides a table showing for each of six criteria air pollutants $\left(\mathrm{SO}_{2}\right.$, particulates, nitrogen dioxide, ozone, carbon monoxide, and lead) which states have imposed a tighter standard than the federal government. Of these six, only $\mathrm{SO}_{2}$ is currently covered by a national-level permit trading system, while the others are covered by federal standards. This model would then suggest that it is more likely for states to impose tighter limits on $\mathrm{SO}_{2}$ than on the other five pollutants.

Indeed, this is what the data show. Nine states have imposed their own tighter standards on $\mathrm{SO}_{2}$, and for four of those states, $\mathrm{SO}_{2}$ is the only one of the six pollutants for which the state set a tighter standard. In contrast, only one state (Hawaii, which is not covered by the $\mathrm{SO}_{2}$ trading program) set its own tighter standard for any of the other five criteria pollutants but did not also set a tighter standard for $\mathrm{SO}_{2}$. This pattern is particularly notable because of these six pollutants, $\mathrm{SO}_{2}$ is the least localized, and thus if all six were regulated in the same way at the national level, $\mathrm{SO}_{2}$ would be the one least likely to face more stringent state standards. 
Another notable national example of pollution trading was the phase-out of leaded gasoline. That program allowed trading among gasoline refiners from 1982-87. But it was effectively a trading program even before that, because the standard required each refiner to keep the average level of lead in the gasoline it produced below a given level, thus effectively allowing trading within each firm. If each refining firm sells gasoline in multiple states, this produces state-level incentives that are essentially the same as under a full trading program. The national-level regulations on leaded gasoline were announced in 1973 and took effect (after being delayed by litigation) in 1976. And in 1976, California imposed its own tighter standard on lead in gasoline.

Similarly, the Corporate Average Fuel Economy (CAFE) standards do not allow trading across different manufacturers, but do average across the vehicles produced by a given manufacturer, and thus provide state-level incentives very similar to those under a tradable permit program. Thus, this model would predict that one or more states would choose to impose their own tighter fuel economy regulations. However, the national CAFE rules specifically forbid states from imposing their own fuel economy rules. But to the extent that states can get around that rule by imposing other regulations that improve fuel economy, this model would predict that at least some would do so.

That is exactly what California tried to do by imposing a greenhouse-gas-per-mile limit, which was then copied by thirteen other states. And that limit was challenged by the federal government because it was effectively equivalent to a fuel economy standard. Goulder et al. (2009) argues that this effort was misguided and not in those states' best interest. The model 
suggests that the opposite may be true: those states' mistake may not have been in imposing those rules, but in not having imposed them sooner. ${ }^{14}$

\section{Conclusions}

This paper has shown that state governments are much more likely to set their own binding environmental regulations when federal regulation uses emissions taxes or tradable permits than when it uses emissions caps. Under an undifferentiated federal emissions cap, tighter state regulations will necessarily improve welfare. Under a tax, state regulations may reduce welfare, but will be more likely to improve it (and to produce an outcome that is more efficient than under a federal emissions cap), particularly if each state's share of federal emissions tax revenue is relatively close to its share of marginal damages from aggregate national emissions. Under emissions permits, however, the opposite is true: while state regulations can improve welfare, they are more likely to reduce it (and produce a resulting outcome that can easily be less efficient than under either taxes or command-and-control).

These results provide yet another argument in favor of emissions taxes over commandand-control regulation, at least at the federal level, because the incentives under a federal emissions tax make states more likely to impose efficiency-enhancing regulations of their own. Conversely, it provides an argument against tradable permits at the federal level, as well as a potential argument for not allowing states to impose their own regulations on a pollutant that is covered by a national tradable permit system.

Given the strong simplifying assumptions made in this paper's model, a natural direction for future research would be to relax some of those assumptions. In particular, allowing cost

\footnotetext{
${ }^{14}$ This is not to say that this conflict was caused entirely by the factors considered in this paper. For simplicity, this model leaves out many factors that may be important in the real world. In particular, it assumes that each level of government acts to maximize welfare for its citizens, an assumption that many people might question in this case.
} 
spillovers (cases in which the cost of reducing emissions in one state depends on emissions reductions in other states) could be quite interesting. Such cost spillovers could result from many factors, including technological innovation or interstate trade in polluting inputs or outputs. Another natural extension would be to consider how the results would change if firms and/or consumers are mobile.

And, as noted earlier, the general framework developed in this paper could be used to consider federalism in contexts other than environmental policy, such as public good provision or income redistribution. Extending the model in that direction could generate useful insights. 


\section{References}

Adler, Jonathan, 2005. "Jurisdictional Mismatch in Environmental Federalism." New York University Environmental Law Journal 14:130-178.

Cramton, Peter, and Steven Stoft, 2010. "Price Is a Better Climate Commitment," The Economists' Voice: Vol. 7 : Iss. 1, Article 3.

Goulder, Lawrence H., Mark R. Jacobsen, and Arthur A. van Benthem, 2009. "Unintended Consequences from Nested State \& Federal Regulations: The Case of the Pavley GreenhouseGas-per-Mile Limits.” NBER working paper no. 15337.

Nordhaus, William D., 2006. “After Kyoto: Alternative Mechanisms to Control Global Warming." American Economic Review 96(2):31-34.

Oates, Wallace, 1999. "An Essay on Fiscal Federalism.” Journal of Economic Literature 37(3):1120-1149.

Oates, Wallace, 2001. “A Reconsideration of Environmental Federalism.” Resources for the Future discussion paper 01-54.

Oates, Wallace E., and Paul R. Portney, 2003. "The Political Economy of Environmental Policy.” In K.-G. Mäler and J. R. Vincent (eds.), Handbook of Environmental Economics, vol. 1. Amsterdam: Elsevier Science.

Potoski, Matthew, 2001. "Clean Air Federalism: Do States Race to the Bottom?” Public Administration Review 61(3):335-342.

Wellisch, Dietmar, 1995. "Locational Choices of Firms and Decentralized Environmental Policy with Various Instruments.” Journal of Urban Economics 37:290-310. 